\title{
Statistical correlation of spectral broadening in VLF transmitter signal and low-frequency ionospheric turbulence from observation on DEMETER satellite
}

\author{
A. Rozhnoi ${ }^{1}$, M. Solovieva ${ }^{1}$, O. Molchanov ${ }^{1}$, O. Akentieva ${ }^{2}$, J. J. Berthelier ${ }^{3}$, M. Parrot ${ }^{4}$, P. F. Biagi ${ }^{5}$, and \\ M. Hayakawa ${ }^{6}$ \\ ${ }^{1}$ Institute of the Earth Physics, RAS, Moscow, Russia \\ ${ }^{2}$ Institute of Space Research, RAS, Moscow, Russia \\ ${ }^{3}$ Institute CETP, Paris, France \\ ${ }^{4}$ LPCE/CNRS, Orleans, France \\ ${ }^{5}$ Department of Physics, University of Bari, Bari, Italy \\ ${ }^{6}$ University of Electro-Communications, Chofu, Tokyo, Japan
}

Received: 24 June 2008 - Revised: 1 September 2008 - Accepted: 1 September 2008 - Published: 16 October 2008

\begin{abstract}
In our earlier papers we have found the effect of VLF transmitter signal depression over epicenters of the large earthquakes from observation on the French DEMETER satellite that can be considered as new method of global diagnostics of seismic influence on the ionosphere. At present paper we investigate a possibility VLF signalionospheric turbulence interaction using additional characteristic of VLF signal-spectrum broadening. This characteristic is important for estimation of the interaction type: linear or nonlinear scattering. Our main results are the following:
\end{abstract}

- There are two zones of increased spectrum broadening, which are centered near magnetic latitudes $\Phi= \pm 10^{\circ}$ and $\Phi= \pm 40^{\circ}$. Basing on the previous case study research and ground ionosonde registrations, probably it is evidence of nonlinear (active) scattering of VLF signal on the ionospheric turbulence. However occurrence rate of spectrum broadening in the middle-latitude area is higher than in the near-equatorial zone $(\sim 15-20 \%$ in comparison with $\sim 100 \%$ in former area) that is probably coincides with the rate of ionospheric turbulence.

- From two years statistics of observation in the selected 3 low-latitude regions and 1 middle-latitude region inside reception area of VLF signal from NWC transmitter we find a correlation of spectrum broadening neither with ion-cyclotron noise $(f=150-500 \mathrm{~Hz})$, which

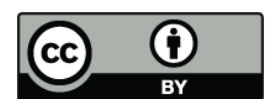

Correspondence to: A. Rozhnoi (rozhnoi@ifz.ru) possibly means poor representation of the turbulence by the noise due to its mixture with natural ELF emission (which correlates with whistler), nor with magnetic storm activity.

- We find rather evident correlation of ion-cyclotron frequency noise, VLF signal depression and weak correlation of spectrum broadening with seismicity in the middle-latitude region over Japan. But in the low-latitude regions we do not find such a correlation. Statistical decrease of VLF signal supports our previous case study results. However rather weak spectrum broadening-seismicity statistical correlation means probably that passive scattering prevails upon nonlinear (active) one.

\section{Introduction}

In our earlier papers we have found the effect of VLF transmitter signal depression over epicenters of the large earthquakes from observation on the French DEMETER satellite that can be considered as new method of global diagnostics of seismic influence on the ionosphere (Molchanov et al., 2006; Rozhnoi et al., 2007). In particular it was shown rather reliable decrease of Australian NWC transmitter signal amplitude several days before and after three large earthquakes (magnitude $\mathrm{M}>6$ ) in Japan region both from satellite and simultaneously on the ground observation (Rozhnoi et al., 2007). We explained the effect by scattering

Published by Copernicus Publications on behalf of the European Geosciences Union. 


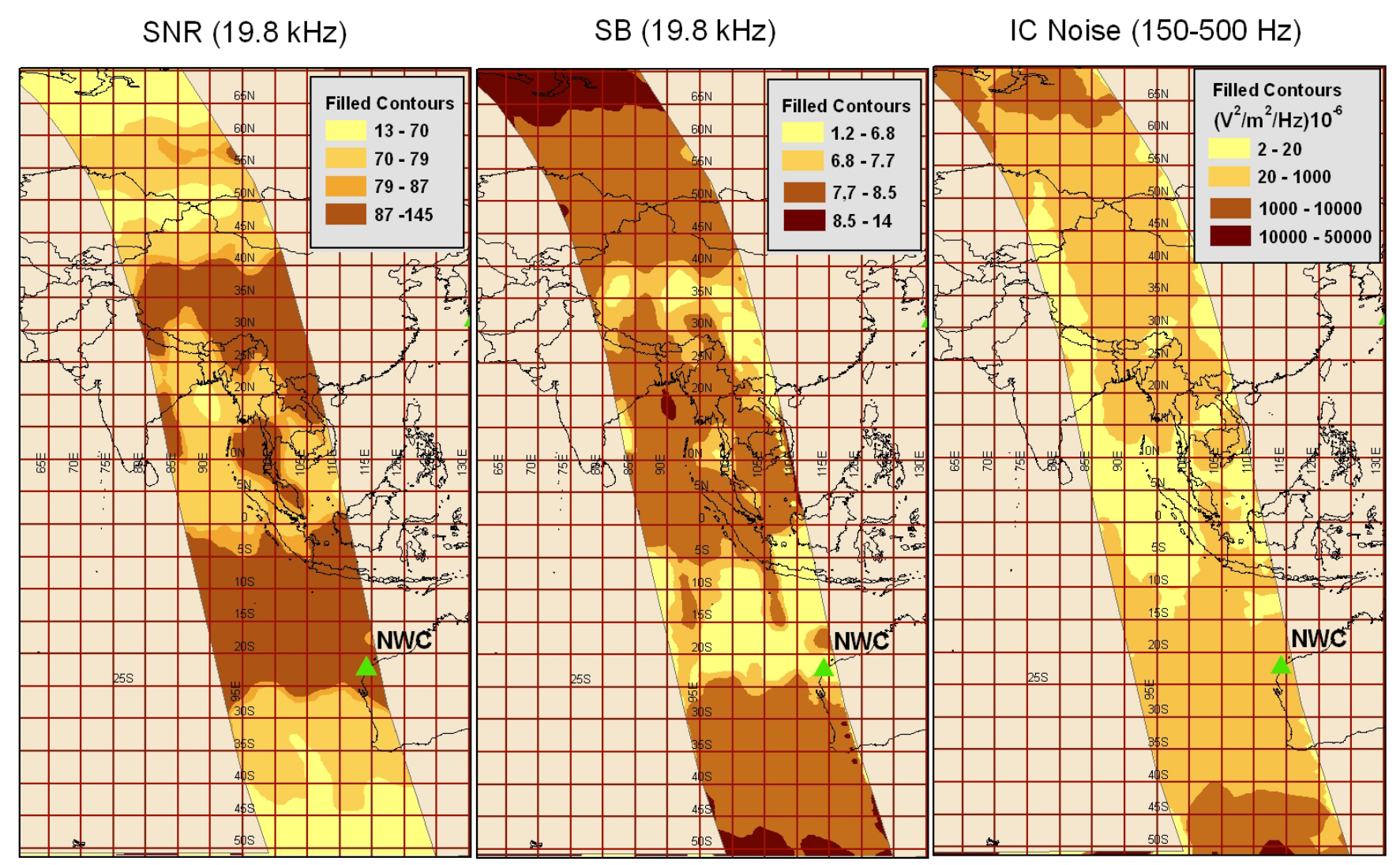

Fig. 1. Distribution of SNR and spectrum broadening for NWC transmitter $(19.8 \mathrm{kHz})$ and ion-cyclotron noise $(150-500 \mathrm{~Hz})$ in the selected longitude segment for the period November 2004-December 2006. The position of NWS transmitter is indicated by green triangle.

of VLF signal on ionospheric turbulence which in its turn was modified by seismicity. Such a modification was reported from statistical analysis of plasma density registration on the Russian satellites Cosmos-900, Intercosmos-24 (Molchanov et al., 2002, 2004) and from plasma-wave observation on the French-Russian satellite Aureol-3 (Hobara et al., 2005). Evidence of seismic ionospheric turbulence stimulation in the ELF frequency range $(100-1000 \mathrm{~Hz})$ near hydrogen ion-cyclotron frequency was discussed in the latter paper. It was found that aside of high-latitude regions (magnetic latitudes $|\Phi|>60^{\circ}$ ) the regular ionospheric turbulence intensification existed near Equatorial Anomaly of plasma density (magnetic latitudes $\Phi= \pm 10-15^{\circ}$ ) and in the middlelatitude areas $\left(\Phi= \pm 30-40^{\circ}\right)$, and it was supposed that just these areas were vulnerable for seismic influence and gave input in statistical estimation. Existence of these two areas of ionospheric turbulence corresponds to well-known areas of small-scale ionospheric irregularities revealed from the ground ionosonde recordings: equatorial and middle-latitude F-spread phenomena (e.g. Kelley, 1989).

At present paper we investigate a possibility VLF signal - ionospheric turbulence interaction using additional characteristic of VLF signal - spectrum broadening (SB). This characteristic is important for estimation of the interaction type: linear or nonlinear scattering. In the first case SB cannot exceed twice of maximal Doppler shift $2 \Delta F<2 \mathrm{FV}_{0} \mu / c \sim 6-$ $60 \mathrm{~Hz}$. Here $F$ is a frequency of the VLF transmitter $\left(F \sim 2 \times 10^{4} \mathrm{~Hz}\right.$ for NWC transmitter), $V_{0}$ is satellite velocity $\left(\sim 7 \times 10^{3} \mathrm{~m} / \mathrm{s}\right), \mu$ is refraction index $(\sim 5-50)$ and $c$ is light velocity $\left(3 \times 10^{8} \mathrm{~m} / \mathrm{s}\right)$. Whereas in a case of non-linear interaction SB can reach the values of hundreds $\mathrm{Hz}$. Indeed this anomalous SB phenomenon was observed in many satellite observations both in high-latitude areas (Bell et al., 1983; Titova et al., 1984) and the middle latitudes (Tanaka et al., 1987) and it was interpreted by mechanism of three-wave interaction of VLF waves and ionospheric turbulence.

\section{Data processing and latitude dependence of spectrum broadening}

We use the night time data of electric field receiver ICE on board of DEMETER satellite in the frequency range $100 \mathrm{~Hz}-$ $20 \mathrm{kHz}$ and analyze signal from powerful Australian NWC transmitter $\left(F=19.8 \mathrm{kHz}, 21.82^{\circ} \mathrm{S}, 114.16^{\circ} \mathrm{E}\right)$. ICE data allow finding power spectrum density with frequency discretization $19.53 \mathrm{~Hz}$ in the selected frequency range and time discretization is $2 \mathrm{~s}$ that corresponds to $15 \mathrm{~km}$ in space along 
each orbit (Berthelier et al., 2006). As for signal we examine the following characteristics: VLF signal amplitude $A_{0}$, signal to noise ratio (SNR), and spectrum broadening of the signal (SB). Signal to noise ratio is calculated as ratio of an average signal spectrum density near the transmitter frequency $F_{0}$ to the minimum value just outside of the signal broadening band: $\mathrm{SNR}=<A_{0}>/ A_{\min }$. This technique was discussed in our previous paper, where it was found that behavior of SNR is the same as $A_{0}$ but allows reducing the sudden spikes (Molchanov et al., 2006). Spectrum broadening of the signal is calculated as follows: $\left.\mathrm{SB}=A_{\text {sum }} /<A_{0}\right\rangle$, where $A_{\text {sum }}$ is the sum of the spectrum densities in the frequency band $F_{0} \pm \delta F$. For our signal $\left(F_{0}=19.8 \mathrm{kHz}\right)$ we selected $\delta F=200 \mathrm{~Hz}$ due to upper limit of the frequency range of $20 \mathrm{kHz}$. Real spectrum broadening (in $\mathrm{Hz}$ ) can be easily found: $R=\mathrm{SB} \times 19.53 \mathrm{~Hz}$, where $19.53 \mathrm{~Hz}$ is frequency resolution in selected frequency range.

As concerned of natural ELF/VLF emission we analyze its intensity in the several bands paying special attention to noise-like emission near hydrogen ion-cyclotron in the range of $150-500 \mathrm{~Hz}$ and width of ion-cyclotron frequency band. Noise intensity is computed as the sum of the spectrum density in the selected frequency band and the width of ioncyclotron band is calculated similar to the spectrum broadening of the VLF signal but in its own frequency range. Unlike the VLF signal where the maximum of the spectrum density is determined by the transmitter frequency, the maximum of the ion-cyclotron noise spectrum density $A_{0 i}$ depends on the latitude. As result we produce a computation of $A_{0 i}$ for each point of an orbit and then estimate the width of ion-cyclotron band.

First of all we investigate latitude dependence of VLF signal spectrum broadening with aim to check its connection with zones of ionospheric turbulence. We select for analysis the space segment which limited by longitudes $100^{\circ}-125^{\circ} \mathrm{E}$ at the initial points of night orbits and magnetic latitudes $\Phi= \pm 60^{\circ}$. A slope of the area coincides with the inclination angle of the orbits (Fig. 1). Since the NWC transmitter is situated in the west coast of Australia the selected area is the zone of stable and strong signal and the width of the area provides one complete orbit every day. Figure 1 shows behavior of SNR, SB and ion-cyclotron noise intensity in selected area for the period November 2004-December 2006. Models were calculated for 120 orbits, which were selected proceeding from the following consideration. Analysis of the spectrum broadening have shown the increase of SB in the region of the middle latitude ionospheric turbulence in the Northern Hemisphere for all the orbits and for nearly the all orbits in the Southern Hemisphere. But in the region of the equatorial ionospheric turbulence the increase of the signal was observed only for about $15-20 \%$ of the orbits. So we selected 120 orbits in the segment (among 650 available orbits during more than 2 years) with increased spectrum broadening in both regions and demonstrate averaged latitude distribution of SNR, SB and ion-cyclotron noise intensity for these
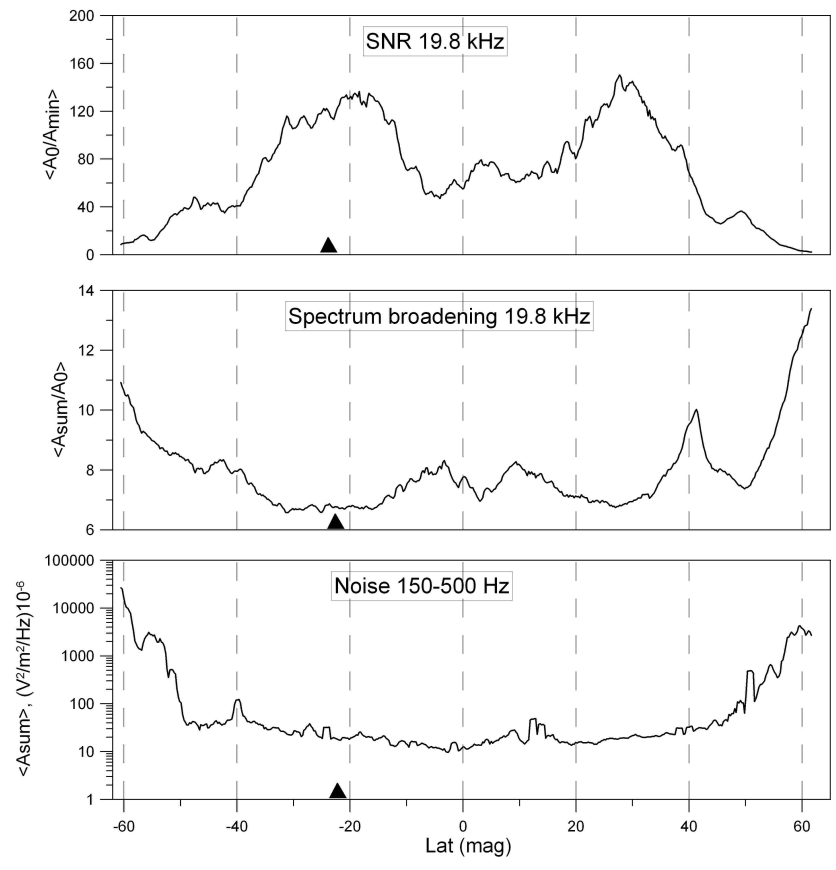

Fig. 2. SNR, SB and ion-cyclotron noise intensity in the same longitude segment averaged over selected 120 orbits. The position of NWS transmitter is indicated by black triangle.

orbits in Fig. 2. It is clear that SNR behavior along an orbit is basically determined by the transmitter position. The signal has maxima above the location of transmitter and in magnetic conjugate region. At the same time the signal doesn't disappear in equator region due to the power of NWS transmitter and the signal slightly decreases in regions of ionospheric turbulence. In regard to SB of the signal it has clear maxima coincided with the supposed regions of ionospheric turbulence. So we conclude that spectrum broadening is connected with ionoshperic turbulence but not with distribution of the VLF signal.

Surprisingly we have no (or weak) indication on connection between ion-cyclotron noise intensity and SB distribution. A possible reason is that the noise behavior is not determined by ionospheric turbulence. Indeed ion-cyclotron noise consists of two parts: natural ELF emission, which is triggered by whistlers or generated by different plasma instabilities and induced electric field oscillations due to satellite movement through quasi-steady density irregularities (ionospheric turbulence). In the latter case a frequency of induced electric field oscillations as follows: $F \sim V_{0} / L$, where $L$ is a scale of density irregularity and $V_{0}$ is satellite velocity (see discussion in Molchanov et al., 2002; Hobara et al., 2005). We show the distribution of ion-cyclotron noise in July and December 2006 in Fig. 3 which can be interpreted as evidence of ion-cyclotron electrostatic wave triggering by whistlers in the magnetically-conjugated areas. In winter whistlers are usually observed at high latitudes of the 


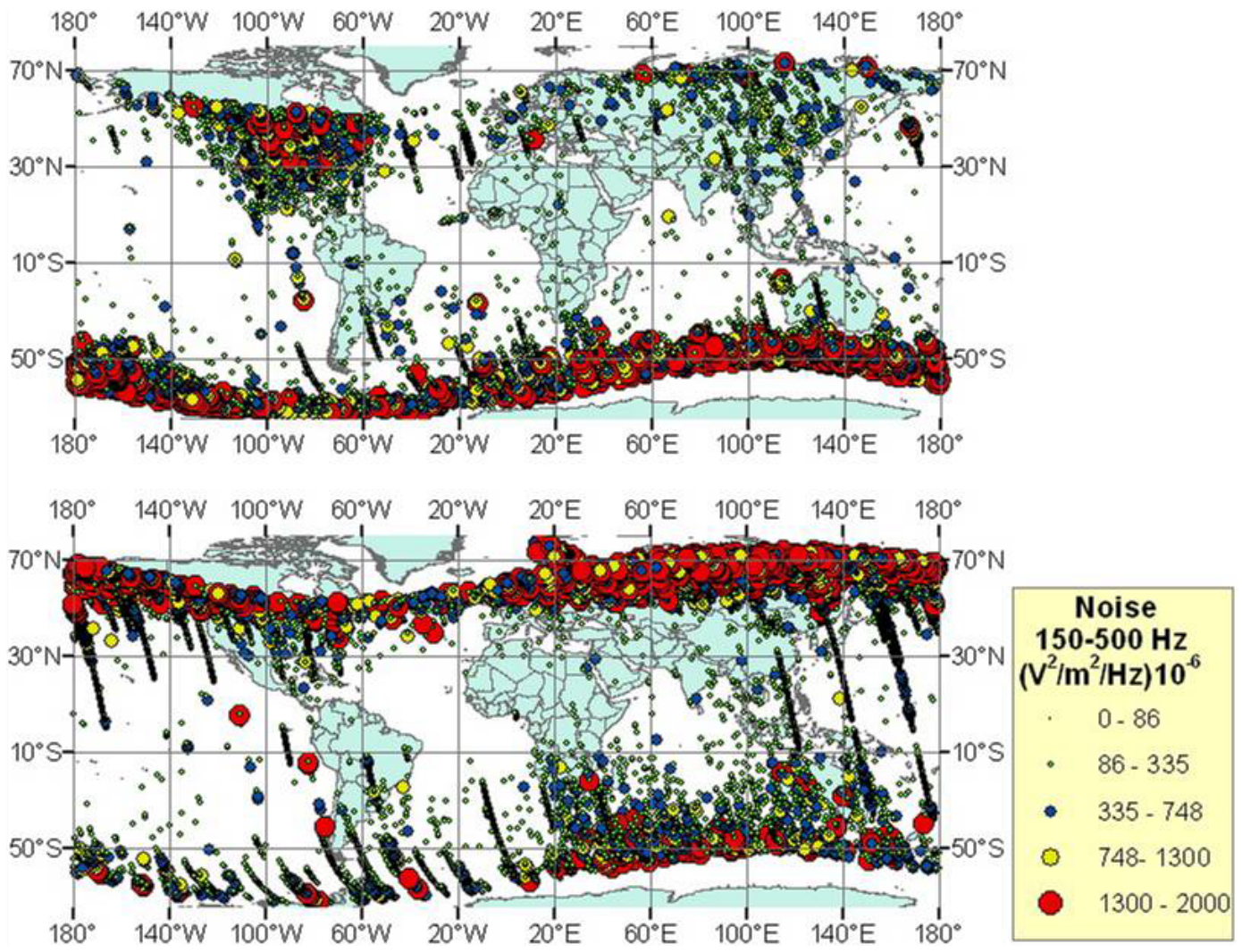

Fig. 3. Distribution of ion-cyclotron noise electric field intensity in 150-500 Hz range for July 2006 (above) and for December 2006 (below).

Northern Hemisphere and in summer there is inverse situation. The behavior of the noise coincides with distribution of the whistlers.

Then we try to find a correlation of VLF signal broadening with width of ion-cyclotron band (noise broadening), which is presented in Fig. 4. These calculations are produced for middle-latitude ionosheric turbulence zone with strong seismicity over Japan (Fig. 5) that is the zone of our previous study (Rozhnoi et al., 2007). The width of the zone is $25^{\circ}$ that provides one orbit every day. SB and width of ion-cyclotron band (noise broadening) are averaged for the part of orbits passed over the zone so we have one value of both characteristics every day. Cross-covariance function was calculated for the period March 2005-December 2006 in the interval \pm 5 days, and days with missing data have not been included in computation. Result shows some correlation of SB of the signal and the width of ion-cyclotron band. Correlation coefficient is about $12 \%$ and its value lager than $95 \%$ of the upper boundary of the interval of reliability for 450 points.

\section{Correlation with magnetic storms and seismicity}

Correlation analysis has been applied for four selected zones with strong seismicity (Fig. 5) in which we use seismic data from USGS catalog. Cross-covariance function was calcu- lated for the period \pm 10 days ( $D_{s t}$ index $)$ and \pm 15 days (seismic magnitude $\mathrm{M}$ ) for ELF/VLF emission in the different frequency bands and also for VLF signal $\left(A_{0}\right)$, SNR and signal SB. Characteristics of DEMETER data are averaged for the part of orbit passed over each zone every day, for $D_{s t}$ index is used the minimal value during a day. Results of correlation with magnetic storm $\left(D_{s t}\right.$ index) are presented in Fig. 6. Correlation with magnetic storms has been found only for ion-cyclotron noise in all zones of analysis and for the ELF noise in $500-1500 \mathrm{~Hz}$ band in region above Japan. For this region some correlation between $D_{s t}$ and VLF spectrum broadening has been revealed too. Correlation coefficient in all these cases surpasses the level of $95 \%$ of the reliability interval.

Finally we show a correlation of characteristics under consideration with seismicity (Fig. 7). Correlation was made for strong earthquakes $(M \geq 6)$ because in our previous papers (Molchanov et al., 2006; Rozhnoi et al., 2007) the effect from strong earthquakes was found in satellite observation. The main problem here is discontinuous of earthquake data. Therefore we have used technique of optimization discrete quantities with the window equal an average half period between events for transformation of discontinuous series into quasi-continuous. At first for every region the average period of time between earthquakes has been estimated. Then in the 

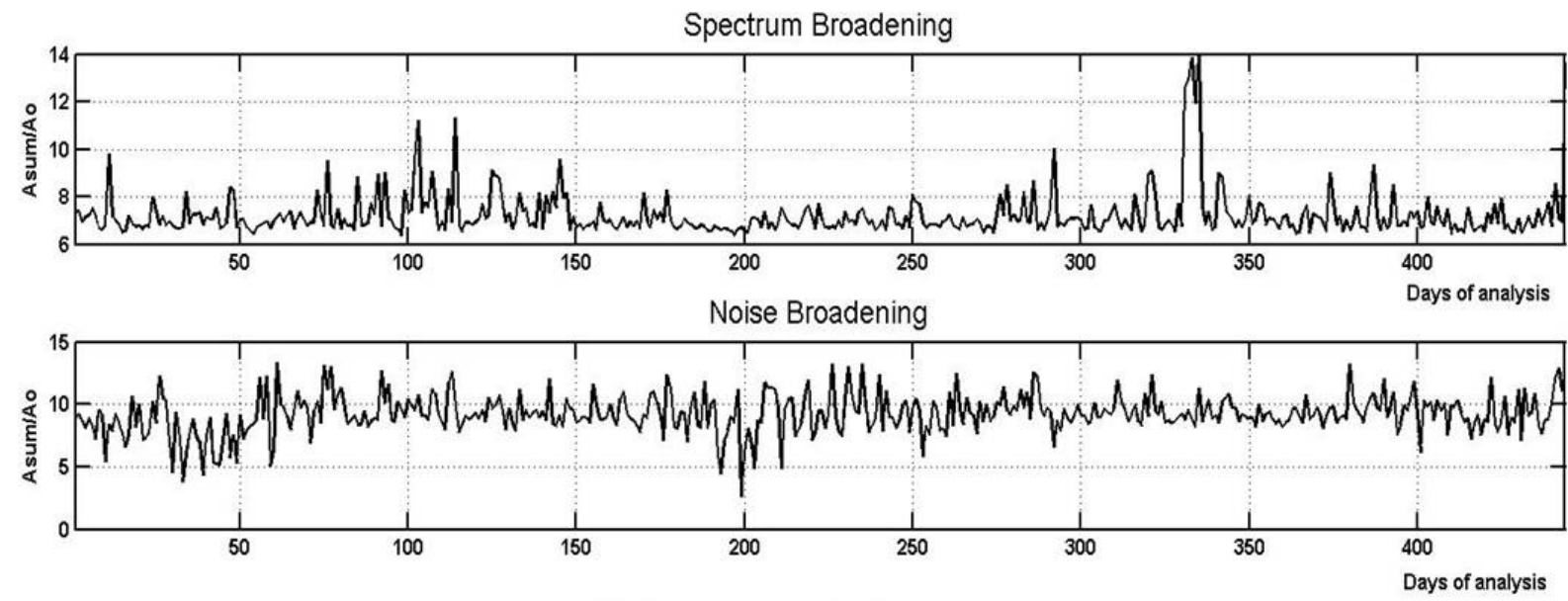

Cross-covariance

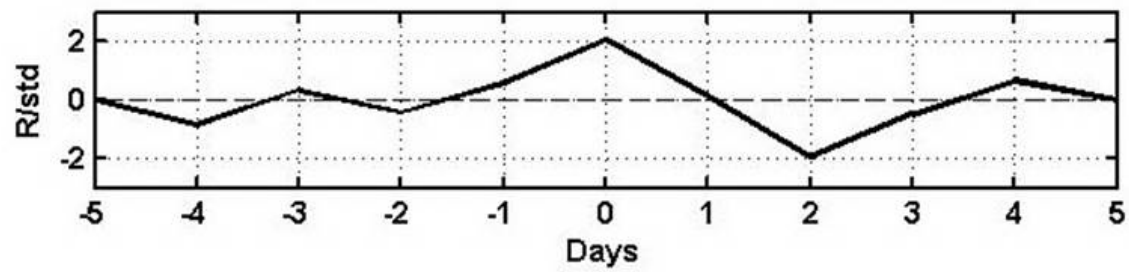

Fig. 4. Correlation of VLF signal spectrum broadening (SB) and width of ion-cyclotron band (noise broadening) in ionosheric turbulence zone over Japan for the period March 2005-November 2006. Two upper panels are spectrum broadening and noise broadening data depending on observation day number (days with missing data are not included in computation). Bottom panel is correlation coefficient normalized to root mean square in the interval \pm 5 days.

windows equal the average half period the values were calculated for every day in both directions as linear decaying from real magnitude $\mathrm{M}$ to 0 . Results of the analysis demonstrate some correlation with seismicity only above Japan region. Decrease of SNR value and increase of ion-cyclotron noise is observed around the date of strong earthquake in this region. Coefficient correlation is about $15 \%$ and it is smaller than $95 \%$ of the upper boundary of the interval of reliability. So the correlation is not significant and it has only type of tendency.

\section{Discussion and conclusions}

Our conclusions are the following:

- There are two zones of increased VLF signal spectrum broadening, which are centered near magnetic latitudes $= \pm 10^{\circ}$ and $= \pm 40^{\circ}$. Basing on the previous case study research (Molchanov et al., 2004; Hobara et al., 2005) and ground ionosonde registrations it is probably evidence of nonlinear (active) scattering of VLF signal on the ionospheric turbulence. However occurrence rate of $\mathrm{SB}$ in the middle-latitude area is higher than in the nearequatorial zone $(\sim 15-20 \%$ in comparison with $\sim 100 \%$

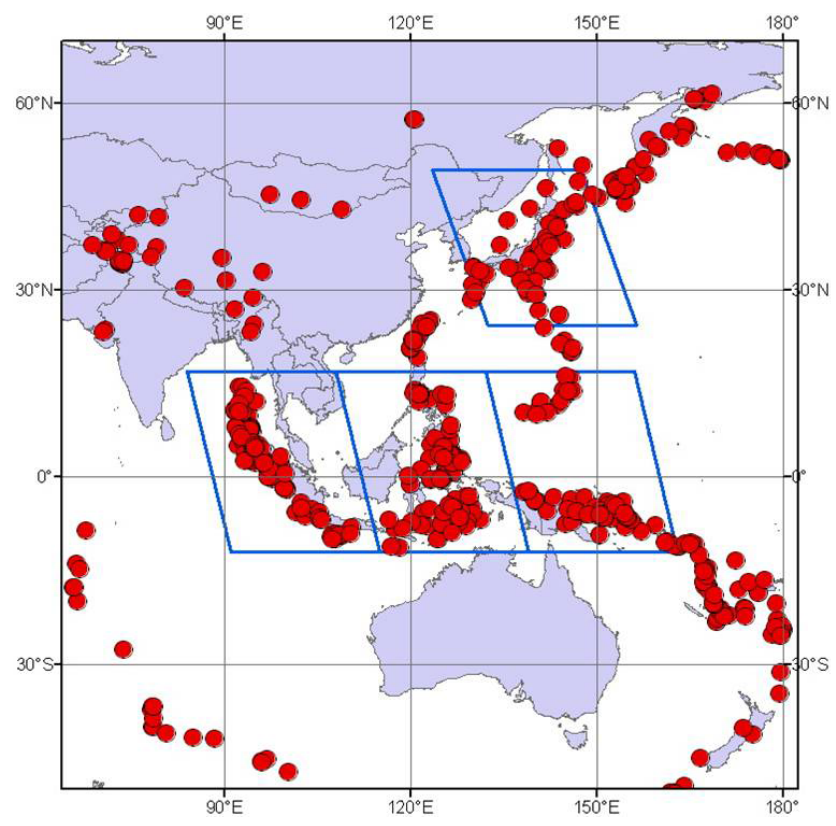

Fig. 5. Zones of analysis with indication of the large earthquake epicenters (M>6) during 2005-2006. 

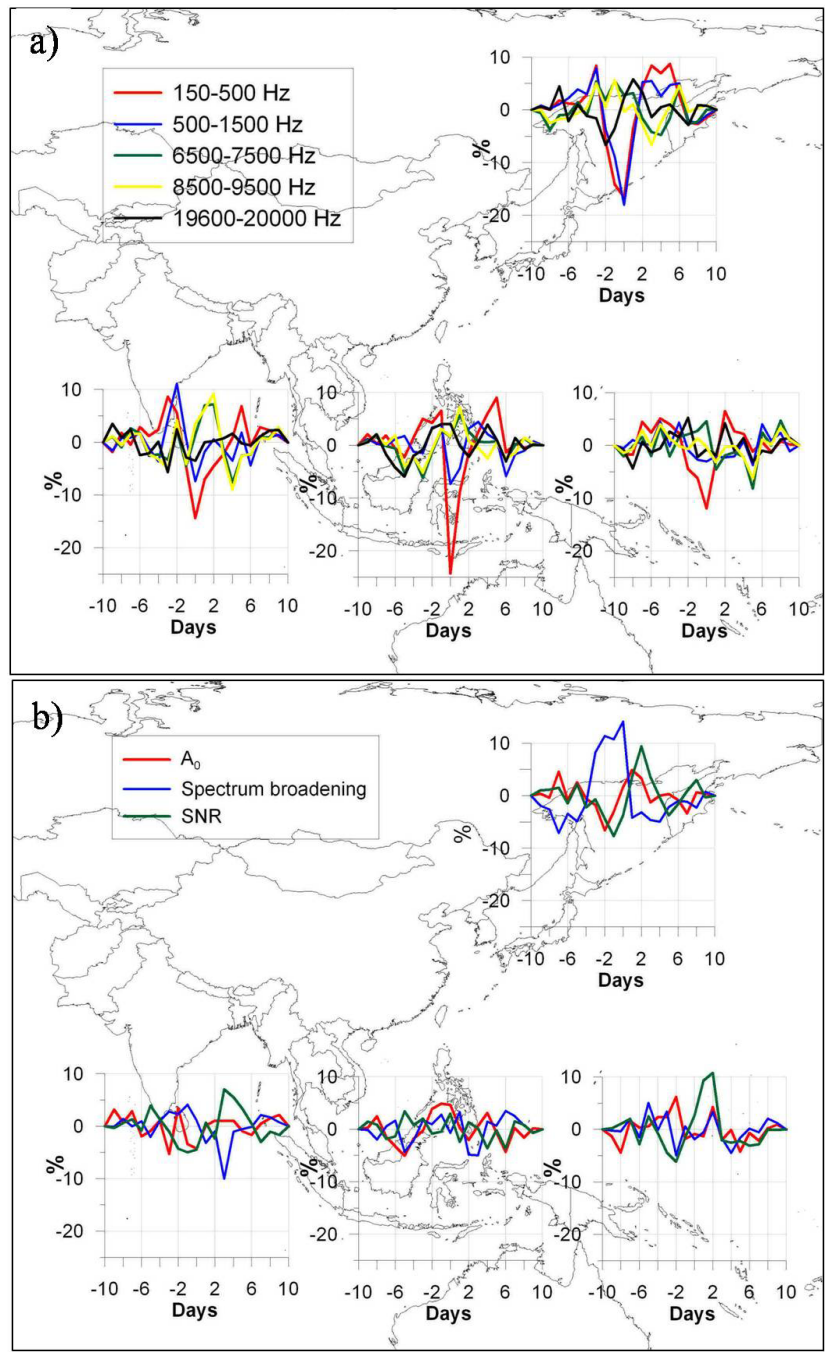

Fig. 6. Correlation with $D_{s t}$ : (a) electric field intensity in the different frequency ranges; (b) $A_{0}$, SNR spectrum broadening $(19.8 \mathrm{kHz})$ for selected zones of analysis.

in former area) that is probably coincides with the rate of ionospheric turbulence.

- From two years statistics of observation in the selected 3 low-latitude regions and 1 middle-latitude region inside reception area of VLF signal we find a correlation of SB neither with ion-cyclotron noise $(f=150-500 \mathrm{~Hz})$, which possibly means poor representation of the turbulence by the noise due to its mixture with natural ELF emission (which correlates with whistler), nor with magnetic storm activity.

- We find rather evident correlation of ion-cyclotron noise, VLF signal depression and weak correlation of SB with seismicity in the middle-latitude region over
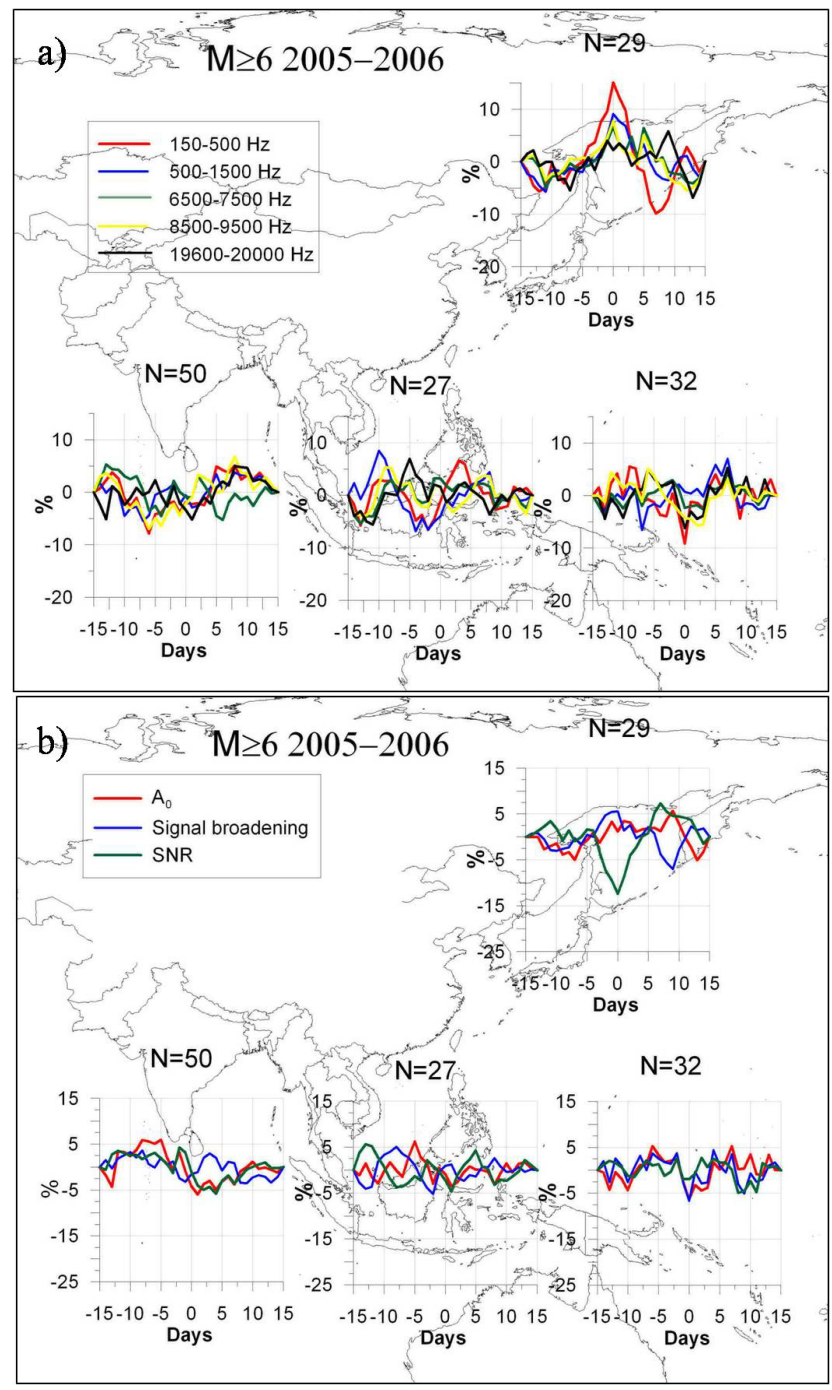

Fig. 7. Correlation with M: (a) electric field variation for different frequency ranges; (b) signal amplitude $\left(A_{0}\right)$, spectrum broadening (SB) and SNR. $N$ - number of earthquakes with $\mathrm{M} \geq 6$ during 20052006 period.

Japan. But in the low-latitude regions we do not find such a correlation.

In order to emphasize the main results of the correlation with seismicity for Japan region they are represented in Fig. 8. Filled areas show an exceeding of the two standard deviation $(2 \sigma)$ level. Although the correlation is not significant, clear decrease of SNR value and increase of ion-cyclotron noise is observed around the date of strong earthquake. The increase of low-frequency emission in 2-3 times were observed during earthquakes in Italy (Bella et al., 1992) and in Japan (Liu et al., 2006) for ground observation. For Japan region statistically was found decrease $f o \mathrm{~F} 2$ in day of earthquake whereas for Taiwan such changes were not detect (Liperovskaya et al., 2006; Liu et al., 2006). Note 

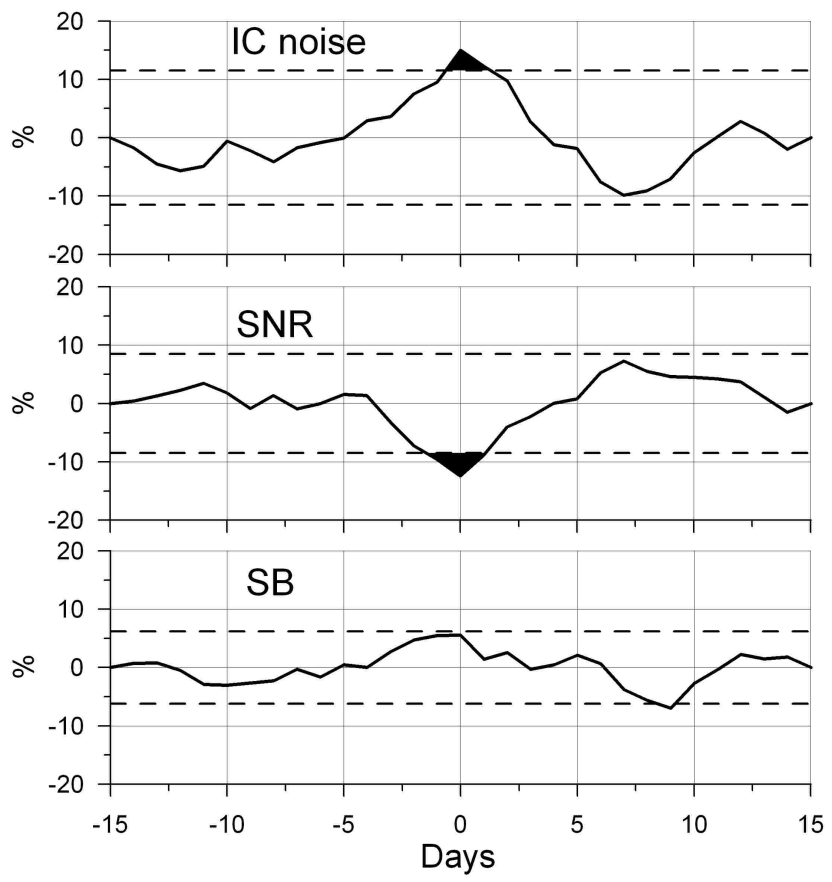

Fig. 8. Correlation of ion-cyclotron noise, SNR and spectrum broadening $(19.8 \mathrm{kHz})$ with $\mathrm{M}$ for Japan region. Dashed lines show two standard deviation $(2 \sigma)$ levels.

that in recent paper Nemec et al. (2008) for DEMETER data statistically was found decrease of the signal in frequency range $1.3-2.4 \mathrm{kHz}$ in day of earthquake $(\mathrm{M} \geq 4.8)$. The evident statistical decrease of SNR value supports by our case studies (Rozhnoi et al., 2007). However rather weak SB-seismicity statistical correlation means probably that passive scattering prevails upon nonlinear (active) one.

Edited by: M. Contadakis

Reviewed by: two anonymous referees

\section{References}

Bell T. F., James, H. G., Inan, U. S., and Katsufrakis, J. P.: The apparent spectral broadening of VLF transmitter signals during transionospheric propagation, J. Geophys. Res., 88, 4813-4816, 1983.

Berthelier, J. J., Godefroy, M., Leblanc, F., Malingre, M., Menvielle, M., Lagoutte, D., Brochot, J. Y., Colin, F., Elie, F., Legendre, C., et al.: ICE, the electric field experiment on DEMETER, Planet. Space Sci., 54, 456-471, 2006.

Bella, F., Biagi, P. F., Della, M. G., Zilpimiani, D. O., Mandzhgaladze, P. V., Pokhotelov, O. A., Sgrigna, V., Ermini, A., and Liperovsky, V. A.: Observations of Natural Electromagnetic Radiation during Earthquakes in Central Italy, Izvestiya, Earth Phys., 28(1), 88-94, 1992.
Hobara, Y., Lefeuvre, F., Parrot, M., and Molchanov, O. A.: Low latitude ionospheric turbulence and possible association with seismicity from satellite Aureol 3 data, Ann. Geophys., 23, 1259-1270, 2005, http://www.ann-geophys.net/23/1259/2005/.

Kelley, M. C.: The Earth's Ionosphere: Plasma Physics and Electrodynamics, Int. Geophys. Ser., 43, 487 pp., Academic, San Diego, Calif., 1989.

Liperovskaya, E. V., Parrot, M., Bogdanov, V. V., Meister, C.-V., Rodkin, M. V., and Liperovsky, V. A.: On variations of $f o \mathrm{~F} 2$ and F-spread before strong earthquakes in Japan, Nat. Hazards Earth Syst. Sci., 6, 735-739, 2006, http://www.nat-hazards-earth-syst-sci.net/6/735/2006/.

Liu, J. Y., Chen, Y. I., Chuo, Y. J., and Chen, C. S.: A statistical investigation of preearthquake ionospheric anomaly, J. Geophys. Res., 111, A05304, doi:10.1029/2005JA01333, 2006.

Molchanov, O. A., Hayakawa, M., Afonin, V. V., Akentieva, O. A., and Mareev, E. A.: Possible influence of seismicity by gravity waves on ionospheric equatorial anomaly from data of IK24 satellite 1 . Search for idea of seismo-ionosphere coupling, in Seismo-Electromagnetics (Lithosphere-Atmosphere-Ionosphere Coupling), edited by: Hayakawa, M. and Molchanov, O., Terrapub, 275-285, 2002.

Molchanov, O. A., Akentieva, O. S., Afonin, V. V., Mareev, E. A., and Fedorov, E. N.: Plasma density-electric field turbulence in the low-latitude ionosphere from the observation on satellites; possible connection with seismicity, Phys. Chem. Earth, 29, 569577, 2004.

Molchanov, O., Rozhnoi, A., Solovieva, M., Akentieva, O., Berthelier, J. J., Parrot, M., Lefeuvre, F., Biagi, P. F., Castellana, L., and Hayakawa, M.: Global diagnostics of the ionospheric perturbations related to the seismic activity using the VLF radio signals collected on the DEMETER satellite, Nat. Hazards Earth Syst. Sci., 6, 745-753, 2006, http://www.nat-hazards-earth-syst-sci.net/6/745/2006/.

Nemec, F., Santolík, O., Parrot, M., and Berthelier, J. J.: Spacecraft observations of electromagnetic perturbations connected with seismic activity, Geophys. Res. Lett., 35, L05109, doi:10.1029/2007GL032517, 2008.

Rozhnoi, A., Molchanov, O., Solovieva, M., Gladyshev, V., Akentieva, O., Berthelier, J. J., Parrot, M., Lefeuvre, F., Hayakawa, M., Castellana, L., and Biagi, P. F.: Possible seismo-ionosphere perturbations revealed by VLF signals collected on ground and on a satellite, Nat. Hazards Earth Syst. Sci., 7, 617-624, 2007, http://www.nat-hazards-earth-syst-sci.net/7/617/2007/.

Tanaka, Y., Lagoutte, D., Hayakawa, M., and Lefeuvre, F.: Spectral broadening of VLF transmitter signals and sideband structure observed on Aureol-3 satellite at middle latitudes, J. Geophys. Res., 92, 7551-7559, 1987.

Titova, E. E., Di, V. L., and Jurov, V. E.: Interaction between VLF waves and the turbulent ionosphere, Geophys. Res. Lett., 11, 323-330, 1984. 